\title{
A comparative study of nested-PCR and direct agglutination test (DAT) for the detection of Leishmania infantum infection in symptomatic and asymptomatic domestic dogs
}

\author{
Yonas Yimam Ayene ${ }^{1} \mathbb{0}$, Mehdi Mohebali ${ }^{1} 2^{*}$, Homa Hajjaran ${ }^{1}$, Behnaz Akhoundi', Saeedeh Shojaee ${ }^{1}$,
} Abbas Rahimi-Foroushani ${ }^{4}$, Mohammad Javad Abbaszadeh Afshar ${ }^{1,3}$ and Z. Zarei ${ }^{1}$

\begin{abstract}
Objective: Canine visceral leishmaniasis (CVL) is the main source of human visceral leishmaniosis (HVL) in Mediterranean region, including Iran and is spread from domestic dogs to Phlebotomine sand flies vectors to humans. To control the transmission of $\mathrm{HVL}$, early and accurate detection of infected dogs is paramount importance despite it remains a confronting challenge. Herein, we evaluated the performance of direct agglutination test (DAT) against gold standard nested polymerase chain reaction (nested-PCR) for CVL diagnosis in symptomatic and asymptomatic domestic dogs from endemic areas of Iran.

Results: Venous blood samples were collected from dogs without clinical signs $(n=30)$ and with clinical signs $(n=35)$ suggestive of Leishmania infantum infection. Among 65 samples examined, Leishmania DNA was detected by nested-PCR in 89.23\% (58/65). Furthermore, 86.15\% (56/65) nested-PCR positive samples were also DAT positive. The results of the DAT sensitivity test were $96.43 \%$ and $96.67 \%$ in symptomatic and asymptomatic dogs, respectively, while the specificity was $100.00 \%$ and $60.00 \%$ in symptomatic and asymptomatic dogs, respectively. The results of this study also pointed out substantial concordance between DAT test and nested-PCR method in both symptomatic dogs $(\mathrm{K}=0.783 ; \mathrm{P}<0.001)$ and asymptomatic dogs $(\mathrm{K}=0.618 ; \mathrm{P}<0.001)$. Thus, DAT represents as a simple and economic tool for initial diagnosis of CVL particularly in endemic areas of the disease.
\end{abstract}

\section{Introduction}

Visceral leishmaniasis is one of the leading lethal parasitic diseases, with a mortality rate of over $90 \%$ of human cases (if left untreated), and domestic dogs are known to be the main resrviour of Leishmania infantum, causative agent of human and canine visceral leishmaniasis(CVL)

\footnotetext{
*Correspondence: mohebali@tums.ac.ir

${ }^{1}$ Department of Medical Parasitology and Mycology, School of Public

Health, Tehran University of Medical Sciences, Tehran, Iran

Full list of author information is available at the end of the article
}

in the South America and Mediterranean basin, including Iran[1-4]. In Mediterranean region, where VL is zoonotic form, the presence of CVL seropositive dogs is strongly associated with human visceral leishmaniasis, highlighting the control of CVL is crucial for bringing down human cases of visceral leishmaniasis $[3,5]$.

Leishmania-infected dogs may exhibit a spectrum of clinical manifestation of the disease, or remain asymptomatic seropositive dogs, depending on the balance between humoral and cellular immune responses [6, 7]. In endemic regions, overt clinical signs were observed in 
less than $50 \%$ of dogs, while most dogs remain asymptomatic for prolonged time and the rate of infectivity of both symptomatic and asymptomatic groups of dogs to sand flies vectors does not significantly differ $[8,9]$. Thus, detection, quantification and mapping of CVL infected dogs irrespective of their clinical status are a paramount importance for controlling human visceral leishmaniasis [10].

While different diagnostic tests are available, such as microscopic examination, culture, serology, and molecular methods, the diagnosis of CVL still remains unsatisfactory [11-14]. Culture technique is time-consuming, invasive and labor-intensive, microscopic analysis requires trained laboratory professionals and lacks sensitivity $[5,10]$. Molecular method has high rates of sensitivity compared to the aforementioned methods; nonetheless, it is expensive and it requires complex laboratory infrastructure, making it difficult to use in the field settings $[15,16]$. Direct agglutination test (DAT) is one of the most widely used diagnosis method for routine laboratory diagnosis and large sero-epidemiological studies in endemic countries like Iran [17]. It doesn't require expertise, it is cost-effective and appropriate for field use [18-20]. Nevertheless, studies have shown that the production of anti-Leishmania antibodies vary depending on the clinical manifestations of the disease and high production of antibodies were evident in symptomatic dogs, so the performance of DAT might vary depending on clinical profiles of dogs $[21,22]$. Thus, this study was carried out to evaluate the accuracy of DAT for detection of
CVL against nested polymerase chain reaction (nestedPCR) from sera samples of symptomatic and asymptomatic domestic dogs in endemic areas of Iran.

\section{Main text \\ Methods}

This study was conducted in the district of MeshkinShahr, Northwest Iran, where CVL is endemic [23]. Between April and May 2019, venous blood samples were collected from 65 domestic dogs (30 symptomatic and 35 asymptomatic dogs) and from five apparently healthy negative control dogs, and blood samples were centrifuged for $10 \mathrm{~min}$ at $800 \mathrm{rpm}$ within $4 \mathrm{~h}$. And separated serum samples were kept at $-20{ }^{\circ} \mathrm{C}$ before usage and serum samples were used for DAT testing and nestedPCR. Experienced veterinarian evaluated the clinical signs of domestic dogs using 14 clinical signs suggestive of $L$. infantum/L. chagasi infection as suggested by Siliva et al. 2017[24], presented in Table 1.

Prior to the commencement of this study, the details of the study were thoroughly reviewed and approved by ethics committee in research, School of Health and Paramedical Sciences, Tehran University (Code of Ethics: IR.TUMS.SPH.REC.1399.022).

\section{Direct agglutination test (DAT)}

DAT antigen for native Iranian strain of $L$. infantum was obtained from Department of Medical Parasitology and Mycology, School of Public Health, Tehran University of Medical Sciences, Tehran, Iran. The main

Table 1 Clinical signs suggestive of L. infantum/L. chagasi infections, according to by Siliva et al. 2017(on score from 0 to 4)

\begin{tabular}{|c|c|c|c|c|c|}
\hline \multirow[t]{2}{*}{ Clinical sign } & \multicolumn{5}{|l|}{ Score } \\
\hline & 0 & 1 & 2 & 3 & 4 \\
\hline Apathy & Active & Apathetic & & & \\
\hline Injuries by ecctoparasite & Absent & Present & & & \\
\hline Weight loss & Absent & Light & Moderate & Intense & $\begin{array}{l}\text { Cachexia with } \\
\text { loss of move- } \\
\text { ment }\end{array}$ \\
\hline Lymphadenomegaly & Absent & Localized & Generalized & & \\
\hline Pale mucous membranes & Absent & Present & & & \\
\hline Bleeding & Absent & Present & & & \\
\hline Cutaneous signs & Bristles & Absent & Present & & \\
\hline Alopecia & Absent & Present & & & \\
\hline Skin lesion & Absence & Presence & Ulcer & & \\
\hline Muzzle depigmentation & Absent & Present & & & \\
\hline Nails & Normal & Onychogryphosis & & & \\
\hline Muzzle/ear lesion & Absent & Present & & & \\
\hline Blepharitis & Absent & Present & & & \\
\hline Keratoconjuctivities & Absent & Present & & & \\
\hline Mucopurulent & Absent & Present & & & \\
\hline
\end{tabular}


phases in the preparation of DAT antigen were mass production of promastigotes L. infantum (MCAN/ IR/07/Moheb-gh) in RPMI1640 plus 10\% fetal bovine serum, trypsinization of the parasites, staining with Coomassie brilliant blue, and fixing with $1.2 \%$ formaldehyde $[17,18,25]$. The dogs' serum samples were examined using DAT for the detection of ant-Leishmania antibody in V-shaped micro titer plates. Serum dilution ranging from initial 1:20 to end point titer of 1:20,000 were prepared and $50 \mu \mathrm{l}$ of antigen suspension was added to each wells. In each plate, negative control well (only antigen) and positive control wells (serum samples with confirmed positive) were prepared for comparison. Afterwards we incubated for $12-18 \mathrm{~h}$ in humid room temperature at $21-24{ }^{\circ} \mathrm{C}$ and then examined agglutination visually. In comparisons with positive and negative controls, compact blue dots were interpreted as negative, while large diffuse blue mats as a positive $[17,19,26]$. The test results were independently examined by two individuals.

\section{Nested-PCR}

DNA extraction from serum specimens was conducted using FavorPrep ${ }^{\mathrm{TM}}$ Tissue Genomic DNA Extraction Mini Kit, in compliance with manufacturer's instructions. All extracted DNA samples were kept at $-20{ }^{\circ} \mathrm{C}$ until used. A two-step nested-PCR assays using the internal transcribed spacer (ITS) region of the SSUrRNA genes was targeted for DNA amplification.In the first step, external primer pairs, (R5' AAACAA AGGTTGTGGGGG3 ${ }^{\prime}$ and 55 AAACTCCTCTCTGGT GCTTGC3') was used for PCR amplification. In the second step, internal primer, (F5'AATTCAACTTCG CGTTGGCC $\left.3^{\prime}\right)$ and R (5'CCTCTCTTTTTTCTCTGT $\mathrm{GC}^{\prime}$ ) was used. The nested-PCR method was carried out as stated in previous study [27]. PCR products were electrophoresed on $1.5 \%$ agarose gel and positive samples were compared with both the DNA ladder and known positive control for identification of Leishmania species.

\section{Data analysis}

The statistical analysis was performed using SPSS Statistical software version 21 and a $P$ value less than 0.5 was considered as statistically significant. The sensitivity (SE), specificity, positive predictive (PPV) and negative predictive value (NPV) of DAT test were calculated as per the formula presented below: Sensitivity $=\mathrm{TP} /(\mathrm{TP}+$ FN $) \times 100 \%$ (TP: true positive, FN: false negative), Specificity $=\mathrm{TN} /(\mathrm{TN}+\mathrm{FP}) \times 100 \%(\mathrm{TN}$ : true negative, FP: false negative), $\mathrm{PPV}=\mathrm{TP} /(\mathrm{TP}+\mathrm{FP}) \times 100 \%$, and $\mathrm{NPV}=\mathrm{TN} /(\mathrm{TN}+\mathrm{FN}) \times 100 \%)$. Kappa statistic $(\mathrm{K})$ test with 95\% Confidence Interval (CI) was used to assess the agreement between DAT test and nested-PCR. K value of $0.40-0.59,0.60-0.79$, and $0.80-0.90$ and above 0.90 were interpreted as weak, moderate, strong and almost perfect agreement, respectively [28].

\section{Results}

The results of DAT and nested-PCR tests for visceral leishmaniosis in dogs with and without clinical signs suggestive of CVL are presented in Table 2. Considering the clinical manifestations of the dogs $(\mathrm{n}=65), 30$ were considered as symptomatic (46.15\%) and 35 (53.85\%) as asymptomatic. Using DAT test, 27 (90.5\%) and 31 $(88.57 \%)$ of symptomatic and asymptomatic dogs were tested positive for CVL, respectively, while the result of nested-PCR showed, 30 (85.71\%) asymptomatic and 28 (93.33\%) symptomatic dogs were found to be infected with CVL. From 65 samples examined by nested-PCR, Leishmania DNA was detected in $89.23 \%$ (58/65). In addition, $86.15 \%(56 / 65)$ of nested-PCR positive samples were also DAT positive. Also, Nested-PCR was able to detect Leishmanial DNA in two dogs (one symptomatic and one asymptomatic dogs) that were not able to detect by DAT.

Considering nested-PCR as gold standard, SE, SP, PPV, NPV and agreement of DAT test with nested-PCR were provided in Table 3. Substantial agreement between DAT and nested-PCR were observed in both symptomatic $(\mathrm{K}=0.783 ; \mathrm{P}<0.001)$ and asymptomatic dogs $(\mathrm{K}=$ $0.618 ; \mathrm{P}<0.001)$. Greater sensitivity were observed in

Table 2 DAT and nested-PCR results for detection of L. infantum infection in symptomatic and asymptomatic dogs from visceral leishmanasis endemic area of Iran, 2019

\begin{tabular}{|c|c|c|c|c|c|c|c|c|c|c|}
\hline & & \multicolumn{3}{|c|}{ Symptomatic dogs $(n=30)$} & \multicolumn{3}{|c|}{ Asymptomatic dogs $(n=35)$} & \multicolumn{3}{|c|}{ All dogs $(n=65)$} \\
\hline & & \multicolumn{3}{|c|}{ Nested-PCR } & \multicolumn{6}{|c|}{ Nested-PCR } \\
\hline & & Positive & Negative & Total & Positive & Negative & Total & Positive & Negative & Total \\
\hline \multirow[t]{3}{*}{ DAT } & Positive & 27 & 0 & 27 & 29 & 2 & 31 & 56 & 2 & 58 \\
\hline & Negative & 1 & 2 & 3 & 1 & 3 & 4 & 2 & 5 & 7 \\
\hline & Total & 28 & 2 & 30 & 30 & 5 & 35 & 58 & 7 & 65 \\
\hline
\end{tabular}


Table 3 Evaluation of DAT for detection of CVL in symptomatic and asymptomatic dogs as compared to nested-PCR from visceral leishmanasis endemic area of Iran, 2019

\begin{tabular}{|c|c|c|c|c|c|c|}
\hline & & & Symptomatic dogs $(n=30)$ & & & Asymptomatic dogs $(n=35)$ \\
\hline \multirow[t]{4}{*}{ DAT } & SE & $96.43 \%$ & \multirow{4}{*}{$\begin{array}{l}(\text { Kappa coefficient; } P) \\
(K=0.783 ; P<0.001)\end{array}$} & SE & $96.67 \%$ & \multirow{4}{*}{$\begin{array}{l}(\text { Kappa coefficient; } P) \\
(K=0.618 ; P<0.001)\end{array}$} \\
\hline & SP & $100.00 \%$ & & $\mathrm{SP}$ & $60.00 \%$ & \\
\hline & PPV & $100.00 \%$ & & PPV & $93.55 \%$ & \\
\hline & NPV & $66.67 \%$ & & NPV & $75.00 \%$ & \\
\hline
\end{tabular}

both symptomatic and asymptomatic dogs, while a relatively reduced specificity was observed in symptomatic dogs. PPV showed high accuracy in both symptomatic and asymptomatic dogs, whereas relatively reduced NPV was observed in symptomatic dogs.

\section{Discussion}

Both symptomatic and asymptomatic dogs could harbor L. infantum/L. chagasi which are infective for Phlebotomine sand flies vectors, thereby infected sandflies could spread L. infantum/L. chagasi to humans and other animals $[9,29]$. Therefore, accurate and rapid diagnostic method for diagnosis of CVL in both symptomatic and asymptomatic dogs are of paramount importance for visceral leishmaniasis control $[4,10]$. Though there are plethora of serological tests for diagnosis of CVL, the sensitivity of these diagnostic methods varies depending on the clinical stage of the disease and the immune status of the host $[13,14]$. Studies have pointed out that serological tests have shortcomings in sensitivity, especially in asymptomatic dogs, and consequently could underestimate the rate of Leishmania infection [13, 14]. Taking in to account the need for accurate, simple and cheap tests for diagnosis of CVL $[18,26]$, and scarcity of comparative diagnostic performance studies between serlogical tests and nested-PCR method in endemic areas, this study was carried out to bridge this gap.

In this study, nested-PCR was able to detect Leishmanial DNA in two dogs (one symptomatic and one asymptomatic dogs) that were not able to detect by DAT. Similar to our results, other studies $([30,31])$ have also shown that molecular method able to detect CVL when DAT fail to detect. The better performance of nestedPCR over DAT may be due to its increased sensitivity, which allows it to detect low parasite load [31].

Due to its high sensitivity and easy to perform, DAT is widely used for routine laboratory diagnosis and large scale sero-epidemiological studies in Iran [17, 19]. In this study, DAT test showed high sensitivity (96.43\% in symptomatic and $96.67 \%$ in asymptomatic dogs). Similar to our studies, a number of studies showed high sensitivity (92-100\%) of DAT in symptomatic dogs [26, 31].
Previous studies that assessed the performance of DAT in asymptomatic dogs are scare; nonetheless, a study that evaluated DAT test diagnostic accuracy against real-time PCR demonstrated $98.7 \%$ sensitivity [31]. In that study, the result for specificity (83\%) in asymptomatic group of dogs was superior to the result observed in our study (60\%) [31]. In present study, in asymptomatic dogs, DAT shown to be less specific $(60.00 \%)$ than other studies, that presented 97\% [32] and 91\% specificity [33]. The discrepancy in specificity between the present study and the previous studies may related to challenges in understanding the time between disease development and production of antibodies at detectable level, highlighting the need for a more robust molecular method to augment early detection of infection [15].

The result of this study showed substantial concordance between DAT test and Nested PCR method in both symptomatic dogs $(\mathrm{K}=0.783 ; \mathrm{P}<0.001)$ and asymptomatic dogs $(\mathrm{K}=0.618 ; \mathrm{P}<0.001)$. The agreement observed in this study was lower than a study that compared concordance of DAT with real-time PCR which showed $83 \%$ in dogs with low anti-leishmanial antibody titer and $97 \%$ in dogs with high anti-leishmanial antibody titer [31]. Similarly, another study showed higher agreement (96\%) than this study [32]. The divergence in the results of agreement between this studies and previous studies may partly stem from lack of perfect reference standard [34] which result in the use of heterogeneous reference standard. Also, the discrepancy in the agreement may explained by difference in batches and antigen types used.

\section{Conclusion}

DAT showed high sensitivity in detection of CVL in both symptomatic and asymptomatic dogs, pinpointing DAT could equally important for diagnosis of CVL in dogs with and without clinical signs suggestive of the disease especially in endemic areas of Iran. Nested-PCR was able to detect Leishmanial DNA in both symptomatic and asymptomatic domestic dogs when DAT fail to detect. Nonetheless, further studies involving highly sensitive and specific reference standard tests are needed to better elucidate diagnostic performance of DAT. 


\section{Limitations}

This research is not, however, devoid of limitations. Given that this study is a cross-sectional investigation, there has been limited knowledge of the diagnostic performance of DAT over time based on clinical and clinical-pathological changes, especially in the symptomatic group of dogs. Also, DAT test performance based on parasite loads has not been evaluated.

\section{Abbreviations}

DAT: Direct agglutination test; CVL: Canine visceral leishmaniasis; Nested-PCR: Nested polymerase chain reaction; K: Kappa statistic; SE: Sensitivity; SP: Specificity; PPV: Positive predictive value; NPV: Negative predictive value.

\section{Acknowledgements}

We would like to acknowledge Tehran University of Medical Sciences for providing financial assistance to this study. We would also like to acknowledge Meshkin-Shar Health Center for their cooperation during field activity.

\section{Authors' contributions}

MM: involved in designing and critically reviewing the manuscript, $Y Y$ : involved in data collection, data analysis and drafting the manuscript: $Z Z$ : participated in dtata collection, MJ, AA, SS, HH, and BA: participated in conducting laboratory work, AR: involved in data analysis and interpretation. All authors read and approved the final manuscript.

\section{Funding}

This study was financially supported by Tehran University of Medical Sciences (Grant No 8: 98/33/53/1192).

\section{Availability of data and materials}

Not applicable.

\section{Declarations}

\section{Ethics approval and consent to participate}

The study has been approved by committee in research, School of Health and Paramedical Sciences, Tehran University (IR.TUMS.SPH.REC.1399.022). Dog owners were informed of the study objectives and voluntary verbal and written consent were obtained.

\section{Consent for publication}

Not applicable.

\section{Competing interests}

The authors declare no competing interest.

\section{Author details \\ 'Department of Medical Parasitology and Mycology, School of Public Health, Tehran University of Medical Sciences, Tehran, Iran. ${ }^{2}$ Centers for Research of Endemic Parasites of Iran (CREPI), Tehran University of Medical Sciences, Tehran, Iran. ${ }^{3}$ Department of Medical Parasitology and Mycology, School of Medicine, Jiroft University of Medical Sciences, Jiroft, Iran. ${ }^{4}$ Department of Epidemiology and Biostatistics, School of Public Health, Tehran University of Medical Sciences, Tehran, Iran.}

Received: 26 January 2021 Accepted: 14 June 2021

Published online: 13 July 2021

\section{References}

1. Gramiccia M, Gradoni L. The current status of zoonotic leishmaniases and approaches to disease control. Int J Parasitol. 2005;35(11-12):1169-80.
2. Solano-Gallego L, Koutinas A, Miró G, Cardoso L, Pennisi M, Ferrer L, et al. Directions for the diagnosis, clinical staging, treatment and prevention of canine leishmaniosis. Vet Parasitol. 2009;165(1-2):1-18.

3. Mohebali M. Visceral leishmaniasis in Iran: review of the epidemiological and clinical features. Iran J Parasitol. 2013;8(3):348.

4. Solano-Gallego L, Cardoso L, Pennisi MG, Petersen C, Bourdeau P, Oliva $\mathrm{G}$, et al. Diagnostic challenges in the era of canine Leishmania infantum vaccines. Trends Parasitol. 2017;33(9):706-17.

5. Shokri A, Fakhar M, Teshnizi SH. Canine visceral leishmaniasis in Iran: a systematic review and meta-analysis. Acta Trop. 2017;165:76-89.

6. Ciaramella P, Oliva G, De Luna R, Ambrosio R, Cortese L, Persechino A, et al. A retrospective clinical study of canine leishmaniasis in 150 dogs naturally infected by Leishmania infantum. Vet Rec. 1997;141(21):539-43.

7. Pinelli E, Killick-Kendrick R, Wagenaar J, Bernadina W, Del Real G, Ruitenberg J. Cellular and humoral immune responses in dogs experimentally and naturally infected with Leishmania infantum. Infect Immun. 1994;62(1):229-35.

8. Molina R, Amela C, Nieto J, San-Andres M, Gonzalez F, Castillo J, et al. Infectivity of dogs naturally infected with Leishmania infantum to colonized Phlebotomus perniciosus. Trans R Soc Trop Med Hyg. 1994:88(4):491-3.

9. Alvar J, Canavate C, Molina R, Moreno J, Nieto J. Canine leishmaniasis. Adv Parasitol. 2004;57(3):1-88.

10. Travi BL, Cordeiro-da-Silva A, Dantas-Torres F, Miró G. Canine visceral leishmaniasis: diagnosis and management of the reservoir living among us. PLoS Negl Trop Dis. 2018;12(1):e0006082.

11. de Souza ACA, de Castro RB, dos Santos YL, da Pavione NRT, de Melo AJ, Bahia MT, et al. High performance of ELISA test using recombinant rLiNTPDase2 from Leishmania infantum: a phase II diagnosis of canine visceral leishmaniasis. Acta Trop. 2020;209:1-44.

12. de Castro FE, de Lana M, Carneiro M, Reis AB, Paes DV, da Silva ES, et al. Comparison of serological assays for the diagnosis of canine visceral leishmaniasis in animals presenting different clinical manifestations. Vet Parasitol. 2007;146(3-4):235-41.

13. Lopes E, Sevá A, Ferreira F, Nunes C, Keid L, Hiramoto R, et al. Serological and molecular diagnostic tests for canine visceral leishmaniasis in Brazilian endemic area: one out of five seronegative dogs are infected. Epidemiol Infect. 2017;145(12):2436-44

14. Costa L, Borba A, Castagna C, Carvalho Filho E, Marson F, Junior FS, et al. Evaluation of PCR in the diagnosis of canine leishmaniasis in two different epidemiological regions: Campinas (SP) and Teresina (PI). Brazil Epidemiol Infect. 2015;143(5):1088-95.

15. Magalhães FB, Castro Neto AL, Nascimento MB, Santos WJ, Medeiros ZM, Lima Neto AS, et al. Evaluation of a new set of recombinant antigens for the serological diagnosis of human and canine visceral leishmaniasis. PLoS ONE. 2017;12(9):e0184867.

16. Singh OP, Sundar S. Developments in diagnosis of visceral leishmaniasis in the elimination era. J Parasitol Res. 2015;2015:1-10.

17. Edrissian GH, Hajjaran H, Mohebali M, Soleimanzadeh G, Bokaei S. Application and evaluation of direct agglutination test in serodiagnosis of visceral leishmaniasis in man and canine reservoirs in Iran. Iranian J Med Sci. 1996;21:119-24

18. el Harith A, Slappendel R, Reiter I, van Knapen F, De Korte P, Huigen E, et al. Application of a direct agglutination test for detection of specific anti-Leishmania antibodies in the canine reservoir. J Clin Microbiol. 1989;27(10):2252-7.

19. Mohebali M, Hajjaran H, Hamzavi Y, Mobedi I, Arshi S, Zarei Z, et al. Epidemiological aspects of canine visceral leishmaniosis in the Islamic Republic of Iran. Vet Parasitol. 2005;129(3-4):243-51.

20. Mohebali M, Keshavarz H, Shirmohammad S, Akhoundi B, Borjian A, Hassanpour $\mathrm{G}$, et al. The diagnostic accuracy of direct agglutination test for serodiagnosis of human visceral leishmaniasis: a systematic review with meta-analysis. BMC Infect Dis. 2020;20(1):1-12.

21. de Freitas JCC, Lopes-Neto BE, de Abreu CRA, Coura-Vital W, Braga SL, Reis $A B$, et al. Profile of anti-Leishmania antibodies related to clinical picture in canine visceral leishmaniasis. Res Vet Sci. 2012:93(2):705-9.

22. Almeida MAO, Jesus E, Sousa-Atta M, Alves L, Berne M, Atta AM. Antileishmanial antibody profile in dogs naturally infected with Leishmania chagasi. Vet Immunol Immunopathol. 2005;106(1-2):151-8.

23. Mohebali M, Moradi-Asl E, Rassi Y. Geographic distribution and spatial analysis of Leishmania infantum infection in domestic and wild animal 
reservoir hosts of zoonotic visceral leishmaniasis in Iran: a systematic review. J Vector Borne Dis. 2018;55(3):173.

24. da Silva KR, de Mendonça VRR, Silva KM, do Nascimento LFM, MendesSousa AF, de Pinho FA, et al. Scoring clinical signs can help diagnose canine visceral leishmaniasis in a highly endemic area in Brazil. Mem do Inst Oswaldo Cruz. 2017;112(1):53-63.

25. Akhoundi B, Mohebali M, Babakhan L, Edrissian G-H, Eslami M-B, Keshavarz $\mathrm{H}$, et al. Rapid detection of human Leishmania infantum infection: a comparative field study using the fast agglutination screening test and the direct agglutination test. Travel Med Infect Dis. 2010;8(5):305-10.

26. Mohebali M, Edrissian GH, Nadim A, Hajjaran H, Akhoundi BB, Hooshmand B, Zarei Z, Arshi S, Mirsamadi N, Manouchehri Naeini K, Mamishi S, Sanati AA, Moshfe AA, Charehdar S, Fakhar M. Application of direct agglutination test (DAT) for the diagnosis and seroepidemiological studies of visceral leishmaniasis in Iran. Iran J Parasitol. 2006;1:15-25.

27. Akhavan AA, Mirhendi H, Khamesipour A, Alimohammadian MH, Rassi $Y$, Bates $P$, et al. Leishmania species: detection and identification by nested PCR assay from skin samples of rodent reservoirs. Exp Parasitol. 2010;126(4):552-6.

28. McHugh ML. Interrater reliability: the kappa statistic. Biochem Med. 2012;22(3):276-82.

29. Alvar J, Vélez ID, Bern C, Herrero M, Desjeux P, Cano J, et al. Leishmaniasis worldwide and global estimates of its incidence. PLOS ONE. 2012;7(5):e35671.
30. Mohammadi-Ghalehbin B, Hatam GR, Sarkari B, Mohebali M, Zarei Z, Jaberipour M, et al. A Leishmania infantum FML-ELISA for the detection of symptomatic and asymptomatic canine visceral leishmaniasis in an endemic area of Iran. Iran J Immunol. 2011;8(4):244-50.

31. Mohammadiha A, Haghighi A, Mohebali M, Mahdian R, Abadi A, Zarei Z, et al. Canine visceral leishmaniasis: a comparative study of real-time PCR, conventional PCR, and direct agglutination on sera for the detection of Leishmania infantum infection. Vet Parasitol. 2013;192(1-3):83-90.

32. Oliveira E, Saliba JW, Oliveira D, Dias ES, Paz GF. A prototype of the direct agglutination test kit (DAT-Canis) for the serological diagnosis of canine visceral leishmaniasis. Vet Parasitol. 2016;221:9-13.

33. Da Silva E, Van der Meide W, Schoone G, Gontijo CMF, Schallig H, Brazil R. Diagnosis of canine leishmaniasis in the endemic area of Belo Horizonte, Minas Gerais, Brazil by parasite, antibody and DNA detection assays. Vet Res Commun. 2006;30(6):637-43.

34. Medeiros FAC, Gomes LI, Oliveira E, de Souza CSA, Mourão MV, Cota GF, et al. Development and validation of a PCR-ELISA for the diagnosis of symptomatic and asymptomatic infection by Leishmania (Leishmania) infantum. J Trop Med. 2017;2017:1-10.

\section{Publisher's Note}

Springer Nature remains neutral with regard to jurisdictional claims in published maps and institutional affiliations.
Ready to submit your research? Choose BMC and benefit from:

- fast, convenient online submission

- thorough peer review by experienced researchers in your field

- rapid publication on acceptance

- support for research data, including large and complex data types

- gold Open Access which fosters wider collaboration and increased citations

- maximum visibility for your research: over 100M website views per year

At BMC, research is always in progress.

Learn more biomedcentral.com/submissions 